\title{
Synthesis, Spectroscopic, Structural Characterization, Conductivity and Electrochemical Studies of a Schiff Base Ligand and Its Copper Complexes
}

\author{
Atinafu Abayneh ${ }^{1,2^{*}}$, Tesfay Gebretsadik ${ }^{3}$, Sisay Tadesse ${ }^{2}$, Madhu Thomas ${ }^{3}$ \\ ${ }^{1}$ Department of Chemistry, Mekdela University, Tulu Awulia, Ethiopia \\ ${ }^{2}$ Department of Chemistry, Hawassa University, Hawassa, Ethiopia \\ ${ }^{3}$ Department of Industrial Chemistry, Addis Ababa Science and Technology University, Addis Ababa, Ethiopia \\ Email: ^atinafumekdela@gmail.com, sisaytad@gmail.com, madhu.thomas@aastu.edu.et
}

How to cite this paper: Abayneh, A., Gebretsadik, T., Tadesse, S. and Thomas, M. (2018) Synthesis, Spectroscopic, Structural Characterization, Conductivity and Electrochemical Studies of a Schiff Base Ligand and Its Copper Complexes. Advances in Chemical Engineering and Science, 8, 241-254.

https://doi.org/10.4236/aces.2018.84017

Received: August 31, 2018

Accepted: October 16, 2018

Published: October 19, 2018

Copyright $\odot 2018$ by authors and Scientific Research Publishing Inc. This work is licensed under the Creative Commons Attribution International License (CC BY 4.0).

http://creativecommons.org/licenses/by/4.0/

\begin{abstract}
Schiff base ligand (L) derived from glyoxal and 4-aminoantipyrine was synthesized. The ligand (L) has been characterized by IR, NMR, electronic spectral studies and electrochemical studies. $\mathrm{Cu}(\mathrm{II})$ complexes of a Schiff base ligand (L) from 4-aminoantpyrine and glyoxal having the composition $\left[\mathrm{CuL}_{1}\right] \mathrm{X}_{2}$ where $\mathrm{X}=\mathrm{Cl}^{-}$or $\mathrm{NO}_{3}^{-}$have been prepared and characterized by elemental analysis, electrical conductivity in non-aqueous solvent, infrared and electronic, as well as cyclic voltammetric studies. L acts as a neutral tetradentate ligand coordinating through both the carbonyl oxygen and azomethine nitrogen. On both the complexes both the anions are not coordinated. A square planar geometry is assigned for complexes. The electrochemical studies of ligand show a typical cyclic voltammogram for an irreversible process. While copper(II) complexes show the typical cyclic voltammograms for quasi reversible process.
\end{abstract}

\section{Keywords}

Schiff Base Ligand, Copper(II) Complexes, Cyclic Voltammetry

\section{Introduction}

A large number of Schiff bases and their complexes have been studied for their interesting and important properties, e.g; their ability to reversibly bind oxygen [1], catalytic activity in hydrogenation of olefins and transfer of an amino group [2], photochromic properties [3], and complexing ability towards some toxic 
metals [4]. The high affinity for the chelation of the Schiff bases towards the transition metal ions is utilized in preparing their solid complexes.

Schiff bases are condensation products of primary amines and carbonyl compounds and they were discovered by a German chemist, Nobel Prize winner, Hugo Schiff in 1864 [5]. In the recent decades, Schiff bases have attracted tremendous interests due to their unique properties and extensive applications in many scientific areas, e.g. anticancer [6] and antibacterial [7], biosensor [8], catalysis [2], analytical chemistry [9] and corrosion prevention [10].

Structurally, Schiff base (also known as imine or azomethine) is an analogue of a ketone or aldehyde in which the carbonyl group $(\mathrm{C}=\mathrm{O})$ has been replaced by an imine or azomethine group. Schiff bases are compounds having a formula $R^{\prime} C=N R$ " where $R$ is an aryl group, R' is a hydrogen atom and R" is either an alkyl or aryl group. However, usually compounds where $\mathrm{R}^{\prime \prime}$ is an alkyl or aryl group and R" is an alkyl or aromatic group are also counted as Schiff bases. Schiff base ligands are essential in the field of coordination chemistry, especially in the development of complexes of Schiff bases because these compounds are potentially capable of forming stable complexes with metal ions [11].

During the past two decades, considerable attention has been paid to the chemistry of the metal complexes of Schiff bases containing nitrogen and other donors [12]. This may be attributed to their stability, biological activity and potential applications in many fields such as oxidation catalysis, electrochemistry, etc. In this study, the synthesis of a Schiff base ligand (L) and its $\mathrm{Cu}$ (II) complexes were reported. Their spectral properties and electrochemical behavior were investigated.

\section{Experimental Part}

\subsection{Instrumental Measurements}

IR spectra were recorded on a PERKIN ELMER SPECTRUM 65 FT-IR spectrometer on $\mathrm{KBr}$ pellet in the wave number range of $4000-400 \mathrm{~cm}^{-1}$. Electronic spectral studies were conducted on a GENESY's UV-Visible spectrometer in the wavelength $200-800 \mathrm{~nm}$. Nuclear Magnetic Resonance (NMR) analysis was recorded on a Brukeravance $400 \mathrm{MHz}$ spectrometer with tetramethylsilane as internal standard and DMSO- $\mathrm{d}^{6}$ as solvent. Molar conductivity of the complexes were measured for $10^{-3}$ Molar solution in acetonitrile using a SX713 model conductivity meter. All the electrochemical experiments were carried out using a computerized electrochemical analyzer (BAS CV-50 W) with a conventional three electrode system at room temperature with a glassy carbon electrode (diameter $=3 \mathrm{~mm}$ ) as working electrode, $\mathrm{Ag} / \mathrm{AgCl} /$ as reference electrode and a platinum wire as counter electrode in DMF and electrochemical grade Tetra butyl ammonium hexafluoro phosphate $\left(0.01 \mathrm{~mol} / \mathrm{dm}^{3}\right)$ as the supporting electrolyte.

\subsection{Solvents and Reagents}

The metal salts were prepared from Analar $\mathrm{BDH}$ copper carbonate and the re- 
spective $50 \%$ acids (AR) and crystallising of the salts by evaporation of the solutions on a steam bath. All the solvents used in the present study is of analytical Grade and used without any further purification. Tetrabutylammonium hexafluorophosphate (Fluka), Glyoxal (Aldrich Chem. Co. USA), 4-Aminoantipyrine (Sigma Chem. Co. USA) were also used without any further purification.

\subsection{Preparation of the Schiff Base}

The Schiff base ligand was prepared by the condensation of the $0.44715 \mathrm{~g}(2.2$ mmol) 4-Aminoantpyrine with $0.057 \mathrm{ml}(1 \mathrm{mmol})$ Glyoxal in absolute ethanolic solution (Scheme 1). The resulting mixture was then refluxed for $2 \mathrm{hrs}$. The yellow precipitate formed was filtered and recrystalized from ethanol to give yellow needles.

\subsection{Preparation of the Schiff Base Copper(II) Complexes}

Cupric chloride $0.170 \mathrm{~g}(1 \mathrm{mmole})$ and copper nitrate $0.18756 \mathrm{~g}(1 \mathrm{mmole})$ were dissolved in methanol $5 \mathrm{ml}$ and added in to a refluxing solution of Schiff base $0.4280 \mathrm{~g}(1 \mathrm{mmole})$ in ethyl acetate. The reaction mixtures were refluxed for $3 \mathrm{hrs}$. The complexes were separated as brown solid is cooled, filtered and repeatedly washed with hot ethyl acetate to remove excess ligand if any. It was then dried in a vaccum in a desiccator over $\mathrm{P}_{2} \mathrm{O}_{5}$.

\subsection{Electrochemical Studies}

Electrochemical cyclic voltammetry measurements were performed at room temperature in 3-electrode cell by using a glassy carbon electrode with $0.071 \mathrm{~cm}^{2}$ surface area as a working electrode, while a platinum wire served as the counter electrode and a $\mathrm{Ag} / \mathrm{AgCl}$ quasi reference electrode. A DMF solution of all the ligand and complexes $\left(1 \times 10^{-4} \mathrm{M}\right)$ and tetrabutylammonium hexafloro-phosphate $(0.01 \mathrm{M})$ as supporting electrolyte were used in each measurements. Measurements were made over a potential range between $0 \mathrm{~V}$ to $+1.6 \mathrm{~V}$ for Schiff base ligand $(\mathrm{L})$ while $0 \mathrm{~V}$ to $0.9 \mathrm{~V}$ for the complexes with a scan rate of $0.1 \mathrm{~V} / \mathrm{s}$.

\section{Results and Discussion}

\subsection{Proton NMR Spectra of Ligand (L)}

The ${ }^{1} \mathrm{H}$ NMR spectrum (Figure 1) of the free ligand showed a singlet at 9.25 $\mathrm{ppm}$ due to the imine protons, multiplet in the range $7.1-8.0 \mathrm{ppm}$ due to the aromatic protons, signals appearing at $3.10-3.50 \delta$ correspond to methyl protons near to hetro-cyclic atoms and signals at $2.8-2.10 \delta$ correspond to methyl protons [13] (Table 1).

The Copper(II) complexes are brown solids (Table 2). They are soluble in acetonitrile, dimethyl formamide, ethanol, and methanol, but insoluble in ethyl acetate.

The molar conductance values of the chloride and nitrate complexes of $\mathrm{L}_{1}$ $\left(10^{-3} \mathrm{M}\right.$ solution) in acetonitrile, fall in the range expected for 1:2 electrolytes 


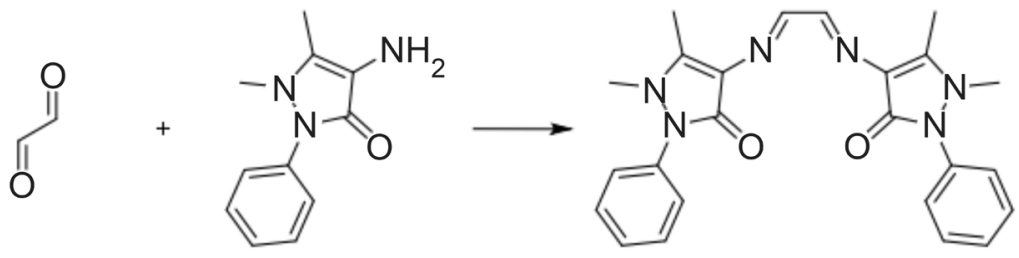

Scheme 1. Synthesis of Schiff base ligand (L).

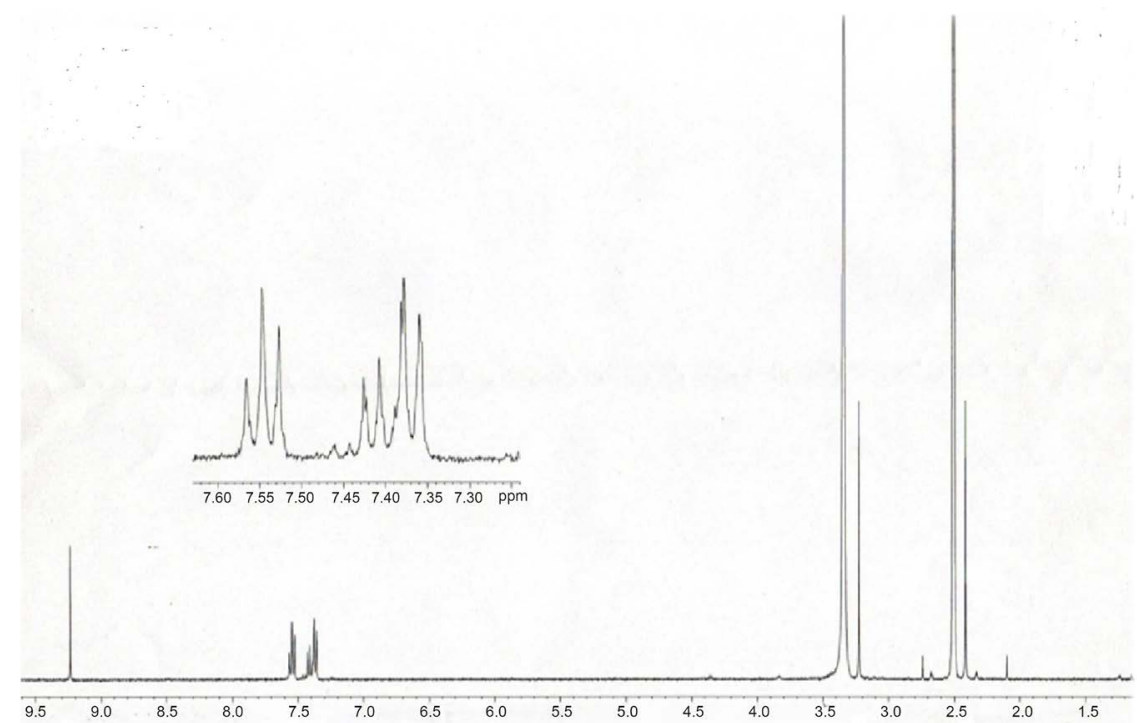

Figure 1. Proton NMR spectra Schiff base ligand L.

Table 1. Chemical shift data of ligand.

\begin{tabular}{ccc}
\hline Compound & Chemical shift $(\delta, \mathrm{ppm})$ & Assignment \\
\hline 9.25 & $\mathrm{CH}=\mathrm{N}$ imine protons \\
$7.8-7.1$ & Phenyl ring protons \\
$3.5-3.1$ & Protons near to hetro-atoms \\
$2.8-2.1$ & Methyl protons \\
\hline
\end{tabular}

Table 2. Elemental analyses and electrical conductance data of copper(II) complexes.

\begin{tabular}{cccccc}
\hline Compound & M. Wt & Color & \% Cu (calcd.) & \% Cu (Found) & $\begin{array}{c}\text { Molar conductance } \\
\left(\Omega^{-1} \cdot \mathrm{Cm}^{2} \cdot \mathrm{mol}^{-1}\right)\end{array}$ \\
\hline$\left[\mathrm{CuL}_{1}\right] \mathrm{Cl}_{2}$ & 562.5 & Brown & $(11.28)$ & $(11.2)$ & 240 \\
{$\left[\mathrm{CuL}_{1}\right]\left(\mathrm{NO}_{3}\right)_{2}$} & 615.5 & Dark brown & $(10.35)$ & $(10.32)$ & 235 \\
\hline
\end{tabular}

[14]. Thus the complexes may be formulated as $\left[\mathrm{CuL}_{1}\right] \mathrm{X}_{2}$ (where $\mathrm{X}=\mathrm{NO}_{3}^{-}$or $\mathrm{Cl}^{-}$).

\subsection{Infrared Spectra of Ligand and Its Copper Complexes}

The important infrared spectral bands of $\mathrm{L}$ and its copper complexes with the tentative assignments are presented in Table 3 and Figures 2-4. 
Table 3. Important infrared spectra bands $\left(\mathrm{cm}^{-1}\right)$ of ligand and its copper complexes.

\begin{tabular}{cccccc}
\hline Compound & $v(\mathrm{C}=\mathrm{O})$ & $v(\mathrm{C}=\mathrm{N})$ & $v(\mathrm{M}-\mathrm{N})$ & $v(\mathrm{M}-\mathrm{O})$ & $\mathrm{V}_{2}$ (ionic nitrate) \\
\hline Ligand $(\mathrm{L})$ & 1659 & 1563 & - & - & - \\
{$\left[\mathrm{Cu}(\mathrm{L})_{1}\right] \mathrm{Cl}_{2}$} & 1635 & 1584 & 502 & 590 & \\
{$\left[\mathrm{Cu}(\mathrm{L})_{1}\right]\left(\mathrm{NO}_{3}\right)_{2}$} & 1620 & 1584 & 520 & 573 & 1374 \\
\hline
\end{tabular}

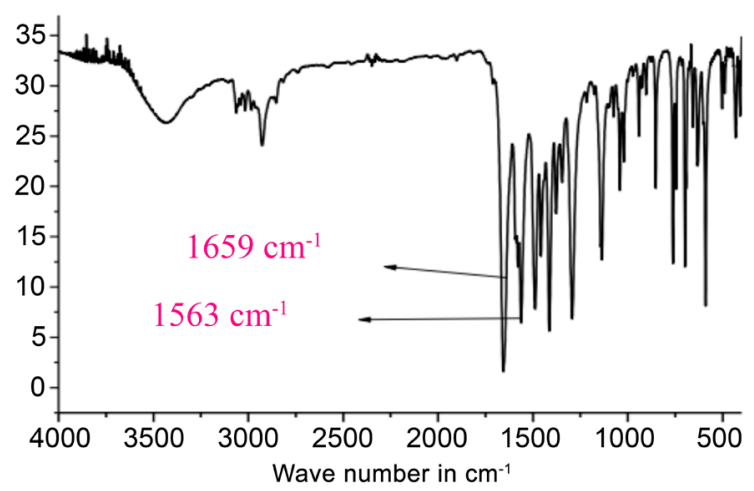

Figure 2. IR spectrum of ligand.

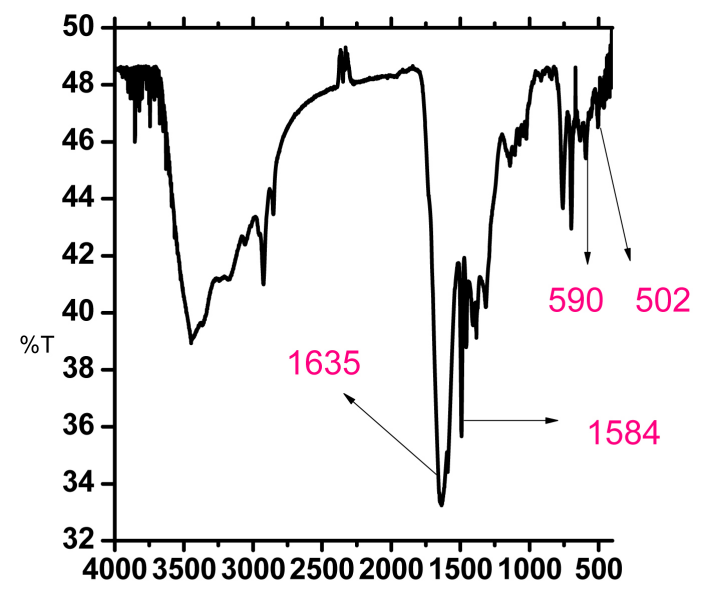

Wave number in $\mathrm{cm}^{-1}$

Figure 3. IR spectrum of chloride complex.

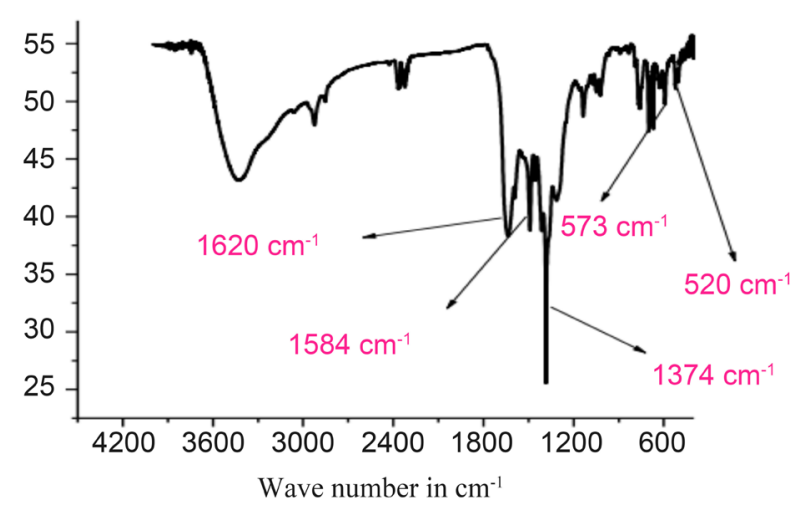

Figure 4. IR spectrum of nitrate complex. 
The infrared spectrum of L exhibits two strong bands at 1659 and $1653 \mathrm{~cm}^{-1}$ corresponding to the stretching vibrations of the carbonyl groups of the ligand, also exhibits a strong band at $1563 \mathrm{~cm}^{-1}$ due to the $\mathrm{C}=\mathrm{N}$ stretching vibration [15]. The infrared band at $1659 \mathrm{~cm}^{-1}$ characteristic of the $v_{\mathrm{C}=\mathrm{O}}$ is shifted to $1635 \mathrm{~cm}^{-1}$ in the chloride complex and 1620 in nitrate complex indicating, the coordination of both carbonyl oxygen to the central metal ion. Also the band at $1563 \mathrm{~cm}^{-1}$ corresponds to $\mathrm{C}=\mathrm{N}$ stretching is shifted to $1584 \mathrm{~cm}^{-1}$ in chloride and nitrate complex indicating the coordination of both azomethine nitrogens to the central metal ion. A strong peak at $1374 \mathrm{~cm}^{-1}$ which is corresponds to the $\mathrm{v}_{2}$ out of plane deformation of the ionic nitrate which is concordance with the conductance data [15]. Further the $v_{\mathrm{Cu}-\mathrm{O}}$ and $v_{\mathrm{Cu}-\mathrm{N}}$ stretching vibrations are observed at about 520 and $502 \mathrm{~cm}^{-1}$ respectively in both complexes.

\subsection{Electronic Spectral Studies}

The electronic spectral bands of $\mathrm{L}$ and its copper complexes with tentative assignments are presented in Table 4 and Figures 5-7.

The electronic spectra of $L$ shows two band maxima at 26,881 and $39,525 \mathrm{~cm}^{-1}$ corresponding to $\mathrm{n} \rightarrow \pi^{*}$ and $\pi \rightarrow \pi^{*}$ transitions respectively [16]. In copper(II) complexes, both the $\mathrm{n} \rightarrow \pi^{*}$ and $\pi \rightarrow \pi^{*}$ bands are found to be blue shifted and appeared in the region $26,178-27,322 \mathrm{~cm}^{-1}$ and $39,840-45,248 \mathrm{~cm}^{-1}$ respectively compared to that of $\mathrm{L}$. The spectra of nitrate complex exhibit a band at $21,739 \mathrm{~cm}^{-1}$ corresponding to the $\mathrm{d}$-d transition consistent with square planar copper(II) complexes. The electronic spectra of chloride complex shows three band maxima at 45,248 and $39,840 \mathrm{~cm}^{-1}$ for $\pi \rightarrow \pi^{*}$ and $27,322 \mathrm{~cm}^{-1}$ corresponding to $\mathrm{n} \rightarrow \pi^{*}$ transitions respectively. In chloride complex, the $\mathrm{d}$ - $\mathrm{d}$ transition cannot be visible because it may be masked by the strong MLCT [16].

Based on the above studies the following tentative structures can be proposed for the complexes (Figure 8).

\subsection{Cyclic Voltammetry}

The ligand (L) and copper(II) complexes were subjected to cyclic voltammetric studies with a view to examine its electrochemical behaviour. A glassy carbon electrode was used as working electrode, $\mathrm{Ag} / \mathrm{AgCl}$ as reference electrode and

Table 4. Electronic spectra data of ligand and copper(II) complexes.

\begin{tabular}{ccc}
\hline Compounds & Abs. max. $\mathrm{cm}^{-1}$ & Tentative assignment \\
\hline Ligand (L) & 39,525 & $\pi \rightarrow \pi^{*}$ \\
& 26,881 & $\mathrm{n} \rightarrow \pi^{*}$ \\
& 45,248 & $\pi \rightarrow \pi^{*}$ \\
{$\left[\mathrm{CuL}_{1}\right] \mathrm{Cl}_{2}$} & 39,840 & $\pi \rightarrow \pi^{*}$ \\
& 27,322 & $\mathrm{n} \rightarrow \pi^{*}$ \\
& 40,000 & $\pi \rightarrow \pi^{*}$ \\
{$\left[\mathrm{CuL}_{1}\right]\left(\mathrm{NO}_{3}\right)_{2}$} & 26,178 & $\mathrm{n} \rightarrow \pi^{*}$ \\
& 21,739 & d-d transition \\
\hline
\end{tabular}




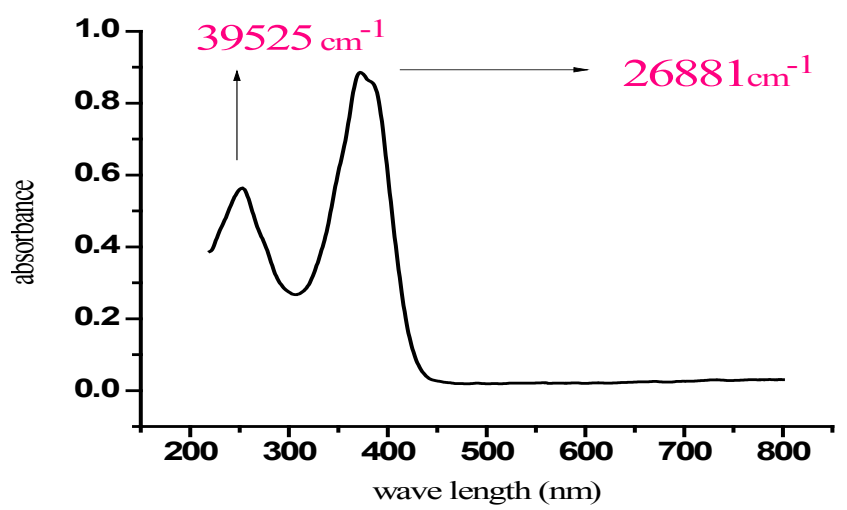

Figure 5. UV-Vis spectrum of ligand.

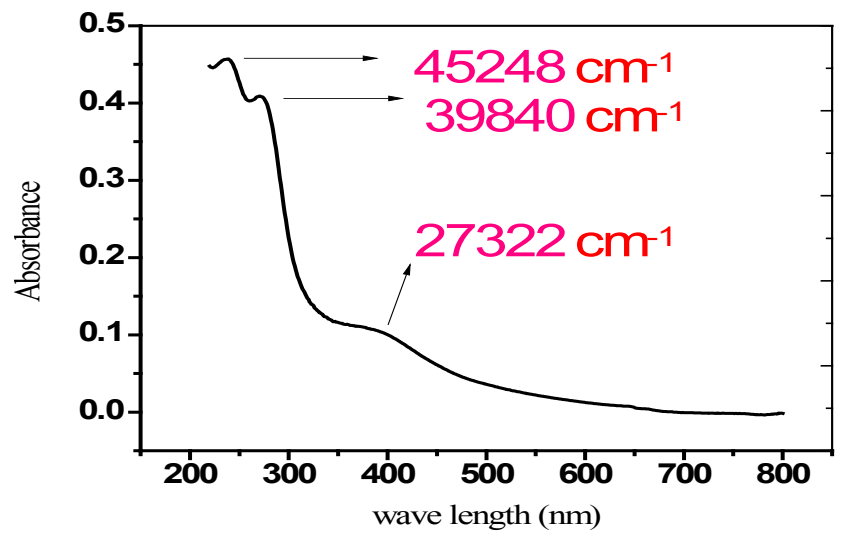

Figure 6. UV-Vis spectrum of chloride complex.

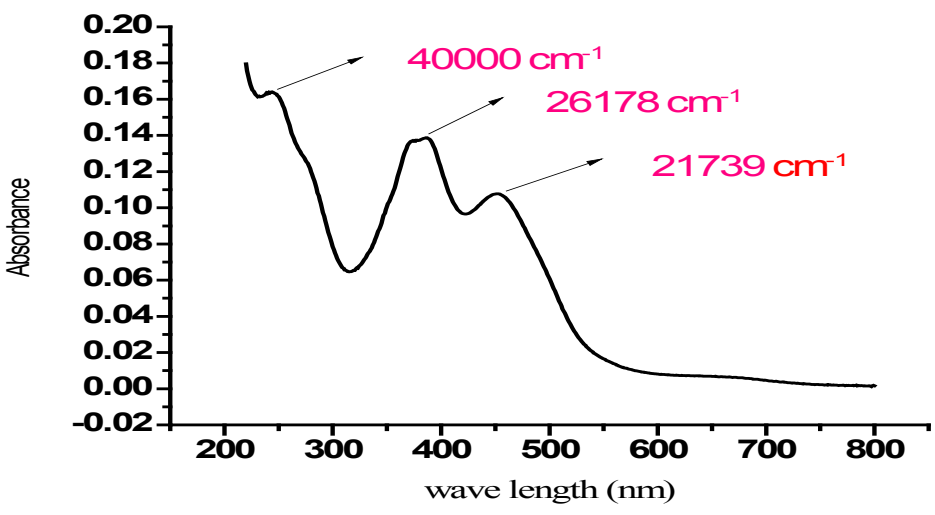

Figure 7. UV-Vis spectrum of nitrate complex.

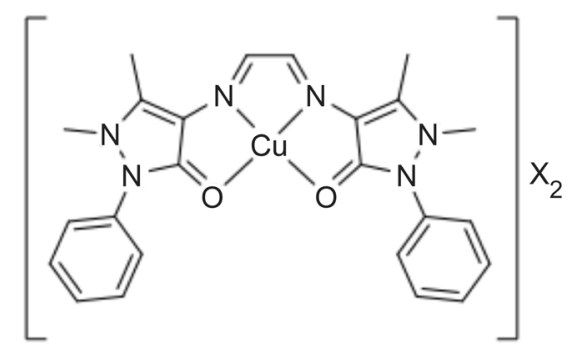

Figure 8. Tentative structures of the $\mathrm{Cu}(\mathrm{II})$ complexes of $\mathrm{L}\left(\mathrm{X}=\mathrm{Cl}^{-}\right.$or $\left.\mathrm{NO}_{3}\right)$. 
platinum wire as auxiliary electrode. The electrochemical studies were conducted with DMF solution of all the ligand and complexes $\left(1 \times 10^{-4} \mathrm{M}\right)$ and tetrabutylammonium hexafloro-phosphate $(0.01 \mathrm{M})$ as supporting electrolyte. Measurements were made over a potential range between $0 \mathrm{~V}$ to $+1.6 \mathrm{~V}$ for Schiff base ligand and $0 \mathrm{~V}$ to $0.9 \mathrm{~V}$ for the corresponding complexes with a scan rate of $0.1 \mathrm{~V} / \mathrm{s}$ (Table 5).

Table 5, Voltammetric data for ligand and complexes in DMF solution containing $0.01 \mathrm{M}$ Tetrabutylammonium hexafluorophosphate. Scan rate (v) $=100 \mathrm{mV} / \mathrm{s}$.

The CV of the Schiff base ligand (L) (Figure 9) which exhibited one irreversible oxidation peak as a result of a large peak separation value $\left(\Delta \mathrm{E}_{\mathrm{p}}=819 \mathrm{mV}\right)$ at $0.100 \mathrm{~V} / \mathrm{s}$ scan rate. A cyclic voltammogram of $\mathrm{Cu}(\mathrm{II})$ chloride complex displays a reduction peak at $\mathrm{E}_{\mathrm{pc}}=-326 \mathrm{mV}$ with an associated oxidation peak at $E_{p a}=712 \mathrm{mV}$ at a scan rate of $100 \mathrm{mV} / \mathrm{s}$. The peak separation of this couple $(\Delta \mathrm{Ep})$ is $386 \mathrm{mV}$. The ratio of anodic to cathodic peak height was greater than one. However, the peak current increases with the increase of the square root of the scan rates. This establishes the electrode process as diffusion controlled [17]. The copper nitrate complex exhibited two quasi-reversible peaks. The representative CV of copper nitrate complex is shown in Figure 10. A cyclic voltammogram of nitrate (Figure 11) displays two reduction peaks. On the first positive potential sweep, the complex shows an anodic oxidation peaks at Epa(I) $=695 \mathrm{mV}$ and $\mathrm{E}_{\mathrm{pa}}(\mathrm{II})=1064 \mathrm{mV}$. The complementary reduction peaks on the negative potential sweep appear at $\mathrm{E}_{\mathrm{pc}}(\mathrm{I})=134 \mathrm{mV}$ and $\mathrm{E}_{\mathrm{pc}}(\mathrm{II})=389 \mathrm{mV}$ : corresponding to the $\mathrm{Cu}(\mathrm{II}) / \mathrm{Cu}(\mathrm{I})$. The value of $\Delta \mathrm{E}_{\mathrm{p}}$ is $561 \mathrm{mV}$ and $675 \mathrm{mV}$ for first and second redox couples respectively and increases with scan rate giving evidence for quasi-reversible nature associated with one electron reduction. The ratio of the anodic to cathodic peak current $\left(\mathrm{I}_{\mathrm{pa}} / \mathrm{I}_{\mathrm{pc}}\right)$ is deviates from one. From these observations it is concluded that the redox process is diffusion controlled.

\subsection{Effect of Scan Rate}

The effect of scan rate could be shown by recorded the CV at concentration of 1 $\times 10^{-4} \mathrm{M}$ of Schiff base ligand. Schiff base ligand L shows the typical cyclic voltammogram for an irreversible process (Figure 12 \& Figure 13). The most obvious indication is the absence of a cathodic reduction signal. Furthermore the oxidation signals significantly shift to more positive potentials with faster scan rates.

Table 5. Voltammetric data of ligand and $\mathrm{Cu}(\mathrm{II})$ complexes.

\begin{tabular}{cccccccc}
\hline & $\begin{array}{c}\text { Scan rate } \\
(\mathrm{mV} / \mathrm{s})\end{array}$ & $\mathrm{I}_{\mathrm{pc}}(\mu \mathrm{A})$ & $\mathrm{I}_{\mathrm{pa}}(\mu \mathrm{A})$ & $\mathrm{i}_{\mathrm{pa}} / \mathrm{i}_{\mathrm{pc}}$ & $\mathrm{E}_{\mathrm{pc}}(\mathrm{mV})$ & $\mathrm{E}_{\mathrm{pa}}(\mathrm{mV})$ & $\Delta \mathrm{Ep}(\mathrm{mV})$ \\
\hline $\mathrm{A}$ & 100 & 0.04 & & & - & 819 & 819 \\
$\mathrm{~B}$ & 100 & 59.2 & 86.2 & 1.456 & 326 & 712 & 386 \\
$\mathrm{C}$ & 100 & 8.9 & 20.4 & 2.29 & 389 & 1064 & 675 \\
\hline
\end{tabular}




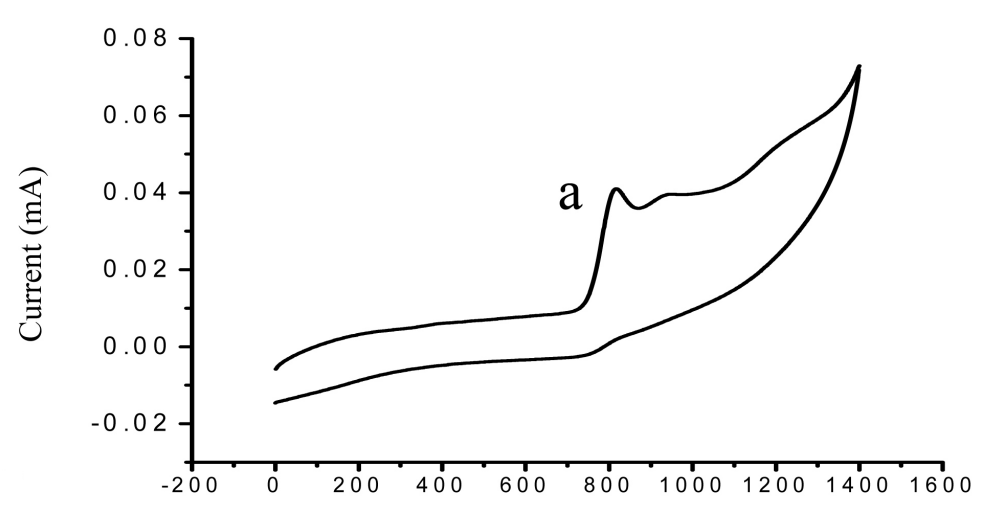

potential (m V) Vs (Ag/AgC 1$)$ quasi reference electrode

Figure 9. Cyclic voltammogram of $1 \times 10^{-4} \mathrm{M}$ of Schiff base ligand at glassy carbon electrode in DMF solution containing 0.01 M Tetrabutylammonium hexafluorophosphate. Scan rate $(\mathrm{v})=100 \mathrm{mV} / \mathrm{s}$.

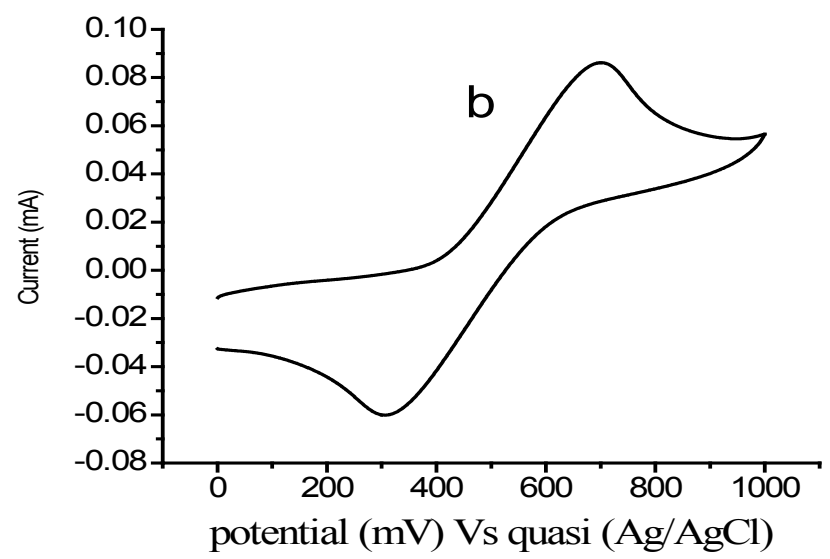

Figure 10. Cyclic voltammogram of $1 \times 10^{-4} \mathrm{M}$ of $\mathrm{Cu}$ (II) chloride complex at glassy carbon electrode in DMF solution containing $0.01 \mathrm{M}$ Tetrabutylammonium hexafluorophosphate. Scan rate $(\mathrm{v})=100 \mathrm{mV} / \mathrm{s}$.

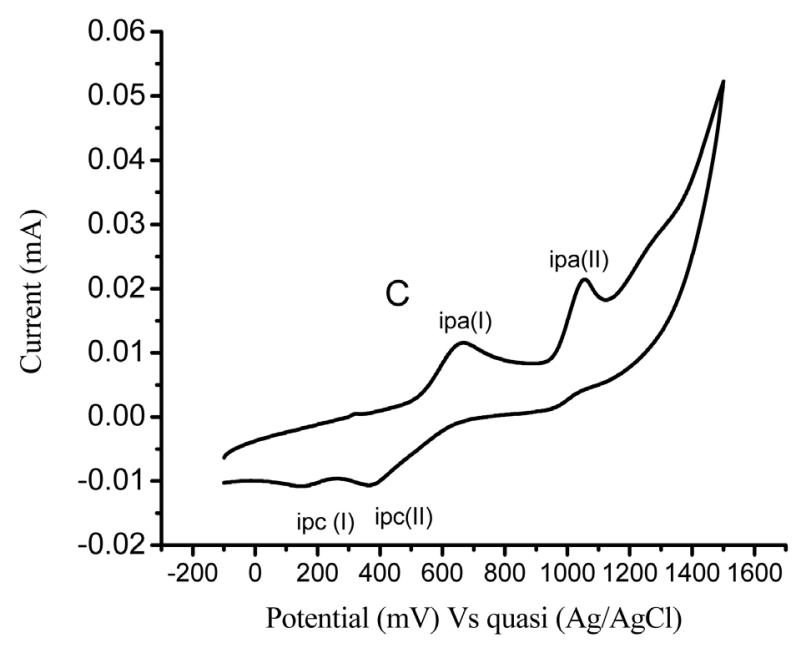

Figure 11. Cyclic voltammogram of $1 \times 10^{-4} \mathrm{M}$ of $\mathrm{Cu}$ (II) nitrate complex at glassy carbon electrode in DMF solution containing $0.01 \mathrm{M}$ Tetra butyl ammonium hexafluoro phosphate. Scan rate $(\mathrm{v})=100 \mathrm{mV} / \mathrm{s}$. 


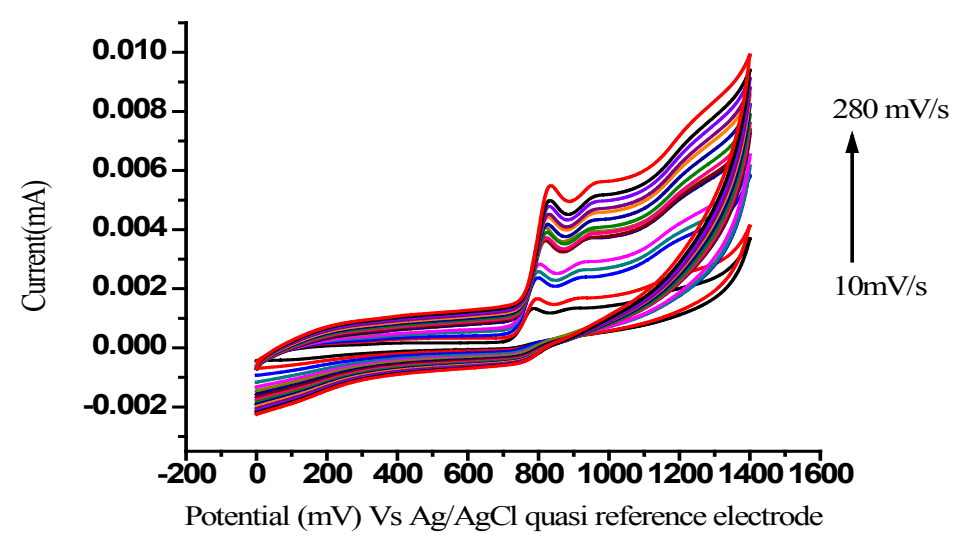

Figure 12. Cyclic voltammograms of schiff base ligand on glassy carbon electrodes in $0.01 \mathrm{M}$ tetrabutylammonium hexaflorophosphate at different scan rates (mV/s): $10-280$ $\mathrm{mV} / \mathrm{s}$.

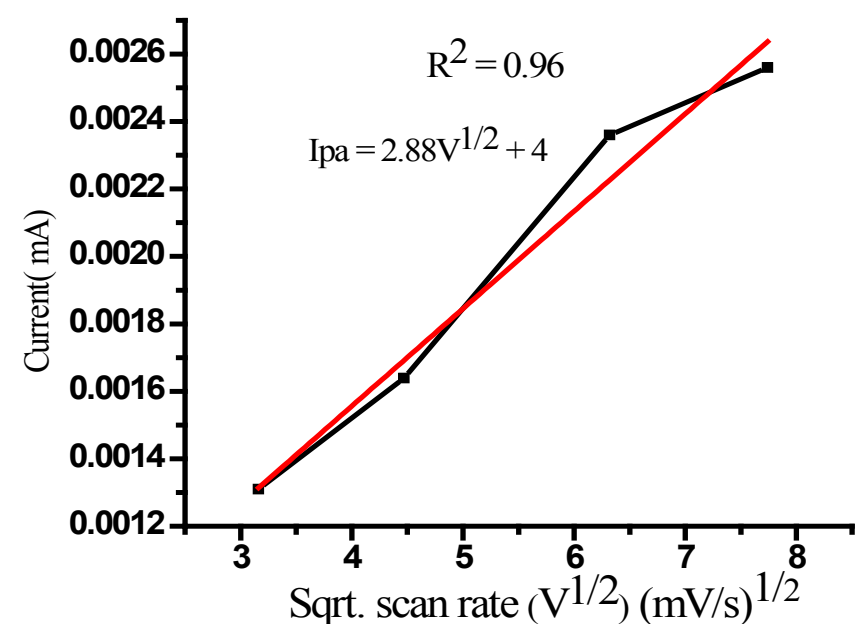

Figure 13. Plot of anodic peak current of Schiff base ligand L as a function of square root of scan rate.

A $1 \times 10^{-4} \mathrm{M}$ concentrations of copper(II) complexes show the typical cyclic voltammograms for quasi reversible process. The cyclic voltammogram will take longer to record as the scan rate is decreased. At a slow scan rate, the diffusion layer will grow much further from the electrode as compared to a fast scan. This leads to a concentration gradient to the electrode surface that is much lower as compared to a fast scan. The peak heights of the anodic signal and the cathodic signal are not completely equal anymore. However, the most obvious indication that the process is not completely reversible anymore is the separation of anodic and cathodic peak potential. The difference of the peak potentials is significantly bigger than $59 \mathrm{mV}$ and the separation of the two signals increases with faster scan rates [18]. Therefore the reaction of copper(II) complexes at higher scan rates can be considered to be quasireversible (Figure 14 \& Figure 15).

For both chloride and nitrate complexes the graph of $i_{p c}$ and $i_{p a}$ against $v^{1 / 2}$ gave a linear plot with $\mathrm{R}^{2}$ greater than 0.98 (Figure 16 \& Figure 17). This indicates that the $i_{p c}$ and $i_{p a}$ were directly proportional to the square root of the scan 


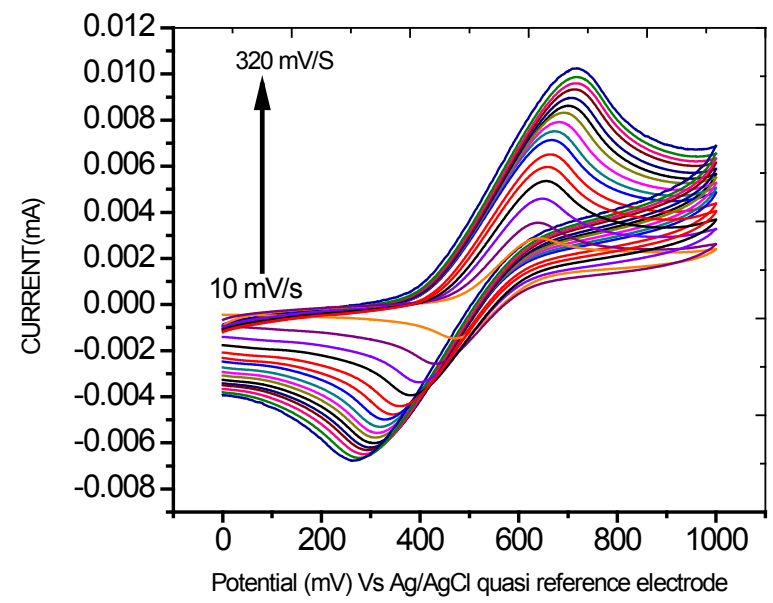

Figure 14. Cyclic voltammograms of chloride complex on glassy carbon electrodes in $0.01 \mathrm{M}$ tetrabutylammonium hexaflorophosphate at different scan rates $(\mathrm{mV} / \mathrm{s}): 10-320$ $\mathrm{mV} / \mathrm{s}$.

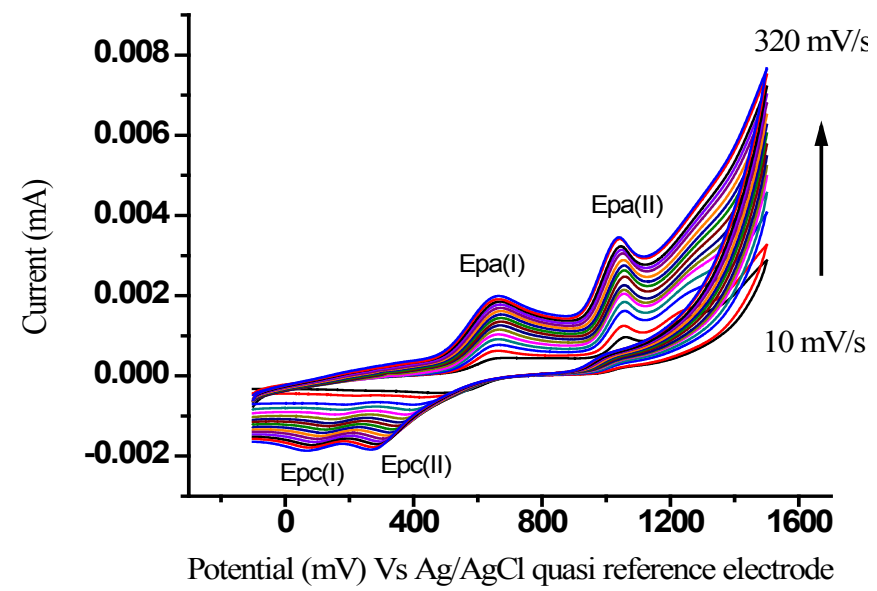

Figure 15. Cyclic voltammograms of nitrate complex on glassy carbon electrodes in 0.01 $\mathrm{M}$ tetra-butylammonium hexaflorophosphate at different scan rates $(\mathrm{mV} / \mathrm{s}): 10-320$ $\mathrm{mV} / \mathrm{s}$.

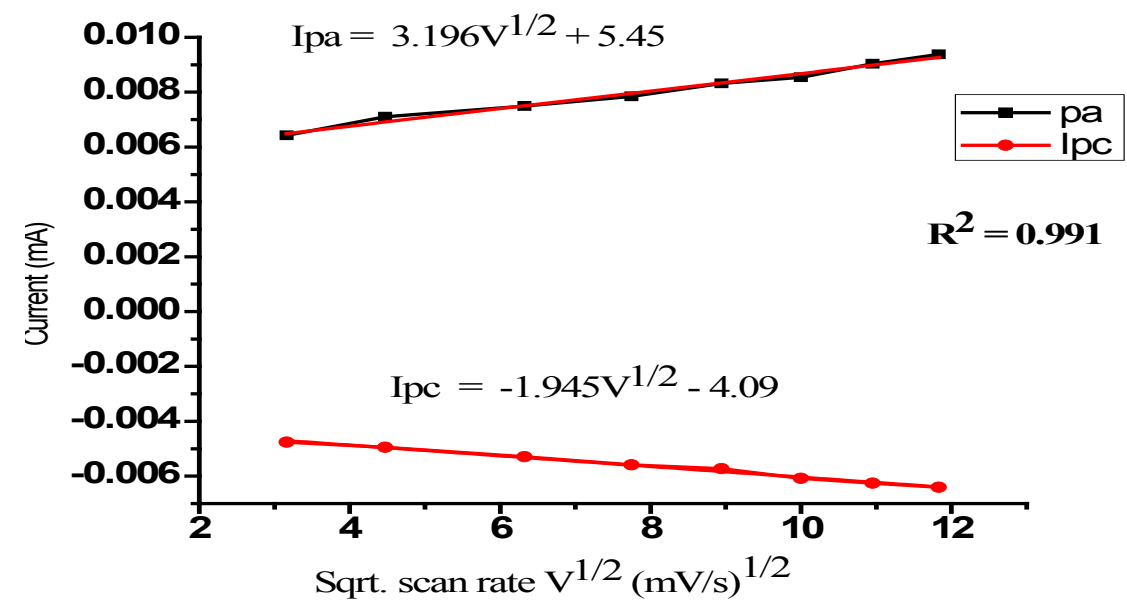

Figure 16. Plot of anodic peak current and cathodic peak current of chloride complex as a function of square root of scan rate. 


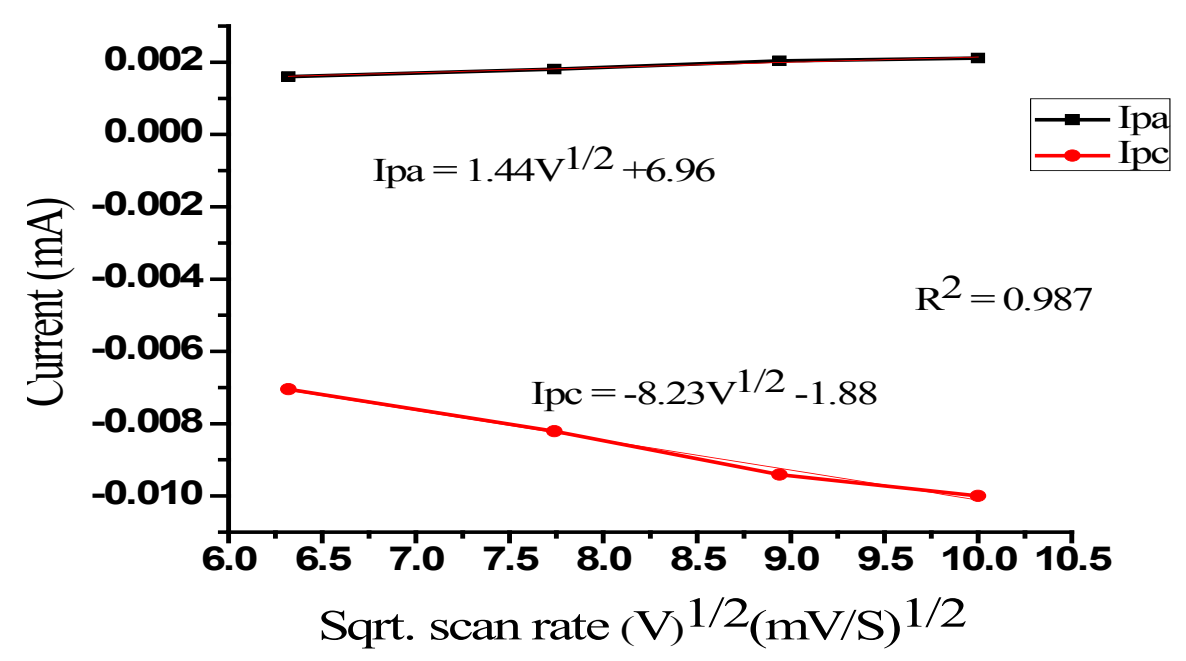

Figure 17. Plot of anodic peak current ( $\mathrm{I}_{\mathrm{pa}}$ (II) and cathodic peak current $\left(\mathrm{I}_{\mathrm{pc}}\right.$ (II) of nitrate complex as a function of square root of scan rate.

rate. From the graph, it also shows that as the scan rate increases, the peak current also increases.

\section{Summary and Conclusion}

The Schiff base ligand (L) and its copper(II) complexes were synthesised and characterised by elemental analyses, molar conductance in non-aqueous solvents, infrared and electronic spectra NMR as well as spectra.

The complexes of $\mathrm{L}$ have the general formulae $\left[\mathrm{Cu}(\mathrm{L})_{1}\right] \mathrm{X}_{2}$ (where $\mathrm{X}=\mathrm{Cl}^{-}$or $\mathrm{NO}_{3}^{-}$). The ligand $\mathrm{L}$ acts a neutral tetradentate ligand, coordinating through both the carbonyl oxygens and both the azomethine nitrogens in the complexes. Both counter anions remain ionic in the complexes. Electronic spectral studies suggest a square planar geometry around the $\mathrm{Cu}(\mathrm{II})$ ion in both the complexes.

The electrochemical studies of ligand show a typical cyclic voltammogram for an irreversible process. The most obvious indication is the absence of a cathodic reduction signal. Furthermore the oxidation signals significantly shift to more positive potentials with faster scan rates.

Copper(II) complexes show the typical cyclic voltammograms for quasi reversible process. The cyclic voltammogram will take longer to record as the scan rate is decreased. At a slow scan rate, the diffusion layer will grow much further from the electrode as compared to a fast scan. This leads to a concentration gradient to the electrode surface that is much lower as compared to a fast scan. The peak heights of the anodic signal and the cathodic signal are not completely equal. However, the most obvious indication that the process is not completely reversible anymore is the separation of anodic and cathodic peak potential. The difference of the peak potentials is significantly bigger than $59 \mathrm{mV}$ and the separation of the two signals increases with faster scan rates. Therefore the reaction of copper(II) complexes at higher scan rates can be considered to be quasi-reversible. 
Future research in this area would benefit from the work incorporated in this paper to study catalytic activity, biological activities and even polymer film formation.

\section{Conflicts of Interest}

The authors declare no conflicts of interest regarding the publication of this paper.

\section{References}

[1] Li, M., Jiao, H., Zhang, H. and Jiao, S. (2015) Electrochemical Polymerization of Schiff Base Transition Metal Polymer Poly[Ni(Salen)] and Its Electrochemical Performance in Organic Electrolyte. International Journal of Electrochemical Science, 10, 8797-8806

[2] Ahmadzadeh, R., Azarkish, M. and Sedaghat, T. (2014) Synthesis, Spectroscopic Characterization, Thermal Analysis and Antibacterial Activity of $\mathrm{Ni}(\mathrm{II}), \mathrm{Cu}(\mathrm{II})$ and $\mathrm{Zn}$ (II) Complexes with Schiff bases Derived from B-Diketones. Journal of the Mexican Chemical Society, 58, 173-179.

[3] Katwal, R., Kaur, H. and Kapur, B.K. (2013) Applications of Copper-Schiff's Base Complexes. Scientific Reviews and Chemical Communications, 3 1-15.

[4] Cozzi, P.G. (2004) Metal-Salen Schiff Base Complexes in Catalysis: Practical Aspects. Chemical Society Reviews, 33, 410-421. https://doi.org/10.1039/B307853C

[5] Deivanayaga, P., Bhoopathy, R.P. and Thanikaikarasan, S. (2014) Synthesis, Characterization, Antimicrobial, Analgesic and CNS Studies of Schiff Base Cu(II) Complex Derived from 4-Choro-O-Phenylene Diamine. International Journal of Advanced Chemistry, 2, 166-170.

[6] Ourari, A., Ouennough, Y., Aggoun, D., Mubarak, M.S., Pasciak, E.M. and Peters, D.G. (2013) Synthesis, Characterization, and Electrochemical Study of a New Tetradentate Nickel(II)-Schiff Base Complex Derived from Ethylenediamine and 5 ( $N$-Methyl- $N$-Phenylaminomethyl)-2-Hydroxy Acetophenone. Polyhedron, 67, 59-64. https://doi.org/10.1016/j.poly.2013.08.056

[7] Jiménez-Pérez, V.M., Muñoz-Flores, B.M., Gómez, J.A., Rangel, L.D., Navarro, R.C., Waksman, N. and Durón, R.R. (2014) Structural Characterization of (E)-4-((4-Nitrobenzylidene)Amino)Phenol Schiff Base. Investigation of Its Electrochemical, Cytotoxic, Antibacterial, and Antifungal Activity. International Journal of Electrochemical Science, 9, 7431-7445.

[8] Shikama, K. (1998) The Molecular Mechanism of Autoxidation for Myoglobin and Hemoglobin: A Venerable Puzzle. Chemical Reviews, 98, 1357-1373. https://doi.org/10.1021/cr970042e

[9] Pradhan, A. and Koshal, A.K. (2015) Synthesis, Characterization and Biological Evaluation of SOME NEW SCHIFF BASES of 1, 3-Bis (P-Chloroanilido) Propane-1, 3-Dione. Journal of Environmental Research and Development, 9, 1168.

[10] Shabbir, M., Akhter, Z., Ahmad, I., Ahmed, S., McKee, V., Ismail, H. and Mirza, B. (2017) Copper (II) Complexes Bearing Ether Based ON Donor Bidentate Schiff Bases: Synthesis, Characterization, Biological and Electrochemical Investigations. Polyhedron, 124, 117-124. https://doi.org/10.1016/j.poly.2016.12.039

[11] Khalil, M.M.H., Ismail, E.H., Mohamed, G.G., Zayed, E.M. and Badr, A. (2012) Synthesis and Characterization of a Novel Schiff Base Metal Complexes and Their 
Application in Determination of Iron in Different Types of Natural Water. Journal of Inorganic Chemistry, 2, 13-21.

[12] Abou-Melha, K.S. (2008) Transition Metal Complexes of Isonicotinic Acid (2-Hydroxybenzylidene)Hydrazide. Spectrochimica Acta Part A: Molecular and Biomolecular Spectroscopy, 70, 162-170. https://doi.org/10.1016/j.saa.2007.07.023

[13] Silverstein, R.M. (2005) Spectroscopic Identification of Organic Compounds. 7th Edition, John Wiley \& Sons, State University of New York, Albany.

[14] Geary, W.J. (1971) The Use of Conductivity Measurements in Organic Solvents for the Characterisation of Coordination Compounds. Coordination Chemistry Reviews, 7, 81-122. https://doi.org/10.1016/S0010-8545(00)80009-0

[15] Nakamoto, K. (1986) Infrared and Raman Spectra of Inorganic and Coordination Compounds. John Wiley \& Sons, New York.

[16] Lever, A.B.P. (1984) Inorganic Electronic Spectroscopy. 2nd Edition, Elsevier, Amsterdam.

[17] Harris, D.A. (1995) Quantitative Chemical Analysis. 4th Edition, W. H. Freeman and Company, New York.

[18] Bard, A.J. and Faulkner, L.R. (2000) Electrochemical Methods: Fundamentals and Applications. 2nd Edition, Wiley, New York. 